\title{
Reproductive Success and Insect Visitation in Wild Roses (Rosa spp.) - Preliminary Results from 2004
}

\author{
Victoria J. MacPhail and Peter G. Kevan \\ University of Guelph, Dept. of Environmental Biology, Guelph, Ontario N1G 2W1 \\ Canada
}

Keywords: hips, fruit set, pollination, reproductive systems, insect observations, pollinators, Hymenoptera, Syrphidae

\begin{abstract}
The hips of wild roses (Rosa spp.) contain many healthful compounds such as vitamins and antioxidants. There is great interest in commercial cultivation but before this can occur, questions regarding plant reproduction and pollinators need to be addressed. Preliminary trials from 2004 investigated the pollination biology of five native or naturalized roses in Ontario and Prince Edward Island, Canada. The reproductive systems of Rosa blanda, $R$. canina, $R$. cinnamomea, $R$. multiflora and $R$. virginiana were investigated through pollination trials, and the potential pollinators of these species were surveyed. Hip and seed production by agamospermy, automatic autogamy, geitonogamy, xenogamy, emasculation control and open-pollination were tested for each species. Reproductive success, the number of hips set over the number of flowers, was calculated for each treatment. Rosa blanda and $R$. multiflora reproduced by open-pollination, geitonogamy and xenogamy; $R$. canina and $R$. virginiana were also autogamous. Both $R$. multiflora and $R$. virginiana set one hip asexually (through agamospermy). Interestingly, $R$. cinnamomea did not set fruit in any treatment or site. Pollinator activity was quantified twice in the season for each species. The number, type (most were hover flies (Syrphidae) or bees (Hymenoptera)), and behavior of insect visitors, as well as the time spent foraging, was recorded during 10 minute intervals on an hourly basis. Insect visitation rates were highest between 0900 and 1200 , and foraging rates peaked sharply at 0900 , indicating the probable period when the most pollen was available. Identified bee genera included Andrena, Apis, Augochlorella, Bombus, Calliposis, Ceratina, Halictus, Hylaeus, Lassioglossum, and Xylocopa.
\end{abstract}

\section{INTRODUCTION}

Wild roses (Rosa spp.) have the potential to become a new crop with economic benefits to farmers and processors. The "fruit" of roses, known as hips, contain many healthful compounds like vitamins, minerals and antioxidants, which are advocated for the prevention of heart disease, stroke, and cancer (Daels-Rakotoarison et al., 2002; Zheng and Wang, 2003; Uggla, 2004). As demand for these compounds increases, pharmaceutical companies, preserve makers, and wineries are interested in acquiring adequate local sources, but first agronomic information, including that on pollination and fruit set, must be obtained.

Roses are hardy, perennial shrubs that can grow in almost all habitats, making them an ideal crop plant (MacPhail, 2004). Wild roses have open 'dish' to 'bowl' shaped, usually single, hermaphroditic flowers, which yield an edible hip (a fleshy or pulpy receptacle) that contains numerous achenes (one-seeded fruits) (Faegri and van der Pijl, 1979; Kevan et al., 1990). Rose hips are used in making tea, jam, jelly, marmalade, puree, wine, and fruit juice (Uggla and Nybom, 1999). They are also eaten by many birds and mammals, often as emergency food in winter (Schneider, 1995). The medicinal use of rose hips is not a new occurrence. They have been used for treating fatigue, eye diseases, heart diseases, insomnia, respiratory diseases, stomach troubles (e.g. diarrhea, dysentry), menstrual cramps, dry skin, inflammation, and for preventing kidney stones and scurvy (Cutler, 2003). Recently, anti-inflammatory, antioxidant, and antimutagenic properties have been shown (Daels-Rakotoarison et al., 2002; Uggla, 2004). Some species' hips may 
contain 20-25 times more vitamin C, by weight, than oranges do (Roland, 1998), and may have an even greater antioxidant capacity than blueberries, cranberries, and other fruits (Zheng and Wang, 2003; Uggla, 2004).

Some flowering plants produce fruit and seed using their own pollen, but others require pollen from a different plant, or no pollen at all (Richards, 1997). Knowledge of rose reproduction is needed to manage the plants for crop production. However, pollination in Rosa has not been well studied experimentally (Kevan et al., 1990). It was once believed that automatic autogamy (self-pollination) occurred in all roses (e.g. Knuth, 1908), but many Rosa species do not set fruit by self-pollination. Low fruit sets from selfpollination can be the result of self-incompatibility (Jičínská, 1975, 1976; Stougaard, 1983; Cole and Melton, 1986; Ueda et al., 1996). This has now been confirmed in several species, including $R$. multiflora and $R$. rugosa (Jičínská, 1976; Stougaard, 1983; Ueda et al., 1996) (but see self-compatibility reported for $R$. multiflora by Wulff (1952) and Kordes (1955) (both cited in Stougaard, 1983)). Many self-compatible species have increased hip set with cross-pollination (Ueda and Akimoto, 2001). Rosa setigera is the only known dioecious rose (Kevan et al., 1990).

Although agamospermy (the production of fruit without fertilization) is common in many rosaceous genera, such as Rubus, Sorbus, and Potentialla (Richards, 1997), researchers are in disagreement as to its' presence in Rosa (Werlemark, 2003). However, several species, especially those in the Caninae section (e.g. $R$. canina), are suspected of having heterogametic or irregular meiosis along with agamospermy (Cole and Melton, 1986; Kevan et al., 1990; Werlemark, 2003).

Roses are insect pollinated (Stougaard, 1983; Kevan et al., 1990). A large variety of beetles, flies, bees and other insects visit rose flowers. Bumble bees, carpenter bees, honeybees, and hover flies are the most common. Other examples include thrips, chafers, and earwigs, which are considered as destructive visitors, and crab spiders, which ambush flower-visiting insects (Stougaard, 1983; Yeboah Gyan and Woodell, 1987; Kevan et al., 1990; Kevan, 2003).

Plant breeding programs for rose hip production have been initiated in many countries, including Czechoslovakia, Bulgaria, Germany, Russia, and Sweden (Jičínská, 1976; Uggla and Nybom, 1999; Uggla, 2004) and are currently being investigated in Canada by the Atlantic Canada Network on Bioactive Compounds (MacPhail, 2004). The purpose of this study was to investigate the reproductive systems of Rosa blanda, $R$. canina, $R$. cinnamomea, $R$. multiflora and $R$. virginiana through pollination trials, and to survey the potential pollinators of each species through insect observation trials and collections.

\section{MATERIALS AND METHODS}

Fifteen sites from southern Ontario, Canada (owned by the Royal Botanical Gardens and the Guelph Arboretum) containing Rosa blanda (4 sites), R. canina (5 sites), and $R$. multiflora (6 sites), and six sites from central Prince Edward Island, Canada (private landowners) containing $R$. cinnamomea ( 2 sites) and $R$. virginiana (4 sites), were used in this study. A site was defined as either a single bush with all ramets coming from a single base (for $R$. multiflora) or a localized patch of roses with many individual ramets growing in close proximity to each other (for all other species). It was assumed that all the ramets within a site were genetically similar to each other (e.g. derived from vegetative reproduction) (i.e. are all part of one plant), and different from all other sites. All sites were wild (un-managed) populations whose origins are unknown.

\section{Reproductive Systems}

Six treatments were replicated five times at $R$. blanda, $R$. canina, and $R$. multiflora sites and eight times at $R$. cinnamomea and $R$. virginiana ones. Therefore a total of 20, 25, 30,16 , or 32 flowers were used in each treatment, for each species respectively, using standard methods. These treatments included 1) agamospermy (no pollination - stigmas, stamens removed; bagged), 2) automatic autogamy (self-pollination - no external 
manipulation; pollen from same flower; bagged), 3) geitonogamy (self-pollination external manipulation; pollen from different flower, same plant; stamens removed; bagged), 4) xenogamy (cross-pollination - external manipulation; pollen from different site of the same species; stamens removed; bagged), 5) emasculation control (control stamens removed; un-bagged), and 6) open-pollination (control - no manipulation) (Kevan et al., 1990; Dafni, 1992; Ueda and Akimoto, 2001; Dafni et al., 2005).

Flowers at the "late-pink" bud stage (petals just starting to show through sepals) were selected (i.e. before anthesis and anther dehiscence) for use in each of the above treatments. Hand-pollinations of receptive stigmas were carried out (where applicable) using small numbers of freshly collected individual anthers (approx. $30-60 \%$ of total number per donor flower) on June 22-24 ( $R$. blanda, $R$. canina (3 sites), $R$. multiflora), July 3 ( $R$. canina (2 sites)), July 13 ( $R$. cinnamomea), and July 21-22 ( $R$. virginiana), 2004. Donor flowers were un-bagged, first day flowers, as this is the stage where the most pollen appeared to be available. Rosa blanda, R. canina, and $R$. multiflora were pollinated during their second day of bloom, while $R$. cinnammomea and $R$. virginiana were pollinated during their first day, as this is the time of greatest stigma receptivity. All bags were removed about 1 to $1 \frac{1}{2}$ weeks after pollination, well after the period of stigma receptivity ended. In early fall, 2 1/2 months after pollination, any hips that had formed were collected and frozen at approximately $-15{ }^{\circ} \mathrm{C}$. They were then measured, weighed, dissected, and the achenes counted and weighed (data not presented here). Reproductive success was calculated as the number of hips formed per total number of flowers tested. After finding no significant differences between sites for each treatment, data were pooled, and each species was evaluated to determine its' method(s) of reproduction.

\section{Insect Observations}

Insect observation trials were carried out by observing a known number of flowers for ten minutes on an hourly basis from 0800 to 1600 in June, 2004 in Ontario, and 0800 to $1500 \mathrm{~h}$ in July, 2004 in Prince Edward Island (period of most pollinator activity) (Kevan et al., 1990; personal observation). Thirteen sites $(2 R$. blanda, $4 R$. canina, $2 R$. cinnamomea, $2 R$. multiflora and $3 R$. virginiana) were observed twice and information gathered on the number of observed flowers and insects, the type, behaviour and foraging time of flower visitors, and environmental conditions (Kevan et al., 1990; Kearns and Inouye, 1993; Dafni et al., 2005). Observed insects were fitted into one of seven groups: honeybees, bumble bees and large carpenter bees, hover flies, other flies, other bees, beetles, unknown/uncertain insect types, and other insects (including moths, grasshopperand worm- like organisms, aphids and ladybugs). The average visitation rate (total number of visits/total number of flowers/total number of sites), average foraging rate (total seconds spent foraging/total number of flowers/total number of sites), and overall visitation rate (total number of visits/total number of flowers/site over 2 days) were then calculated for each period, making no distinction between floral visitor and true pollinator. Representative visitors were also collected using ethyl acetate fumes and are being identified.

\section{RESULTS AND DISCUSSION}

\section{Reproductive Systems}

There were no significant differences in reproductive success between sites within species for each treatment (Kruskal-Wallis, $\mathrm{p}>0.05$ ), allowing data to be pooled (Fig. 1). Rosa blanda and $R$. multiflora were geitonogamous and xenogamous, (i.e. selfincompatible within flowers but not within the same plant, and predominantly outcrossing), while Rosa canina and $R$. virginiana were automatically autogamous as well as geitonogamous and xenogamous (i.e. self-compatible and out-crossing). The openpollination and emasculation control treatments resulted in hip set in these four species, and $R$. multiflora and $R$. virginiana each had one hip set through agamospermy. Rosa cinnamomea did not set fruit in any treatments. 
Ueda and Akimoto (2001) found $R$. blanda to have a 5\% selfed- (autogamous) fruit set, and $R$. virginiana to have $90 \%$ selfed-fruit set, whereas this study found $5 \%$ for $R$. blanda and $19 \%$ for $R$. virginiana. Jičínská $(1975,1976)$ found $R$. canina to have a $82.2 \%$ and $83.2 \%$ successful fruit set in autogamy, $50 \%$ set in geitonogamy, $37.8 \%$ in xenogamy, and $81.4 \%$ in open-pollinated flowers, while this study had $48 \%, 28 \%, 72 \%$ and $72 \%$, respectively. Both Ueda and Akimoto (2001), Jičínská (1976), and this study found $R$. multiflora to have $0 \%$ automatic selfed-fruit set. Stougaard (1983) tested different clones of $R$. multiflora and found autogamy rates ranging from 0.0 to $1.0 \%$, and xenogamy rates from 71.4 to $92.5 \%$ ( $40 \%$ in this study).

The emasculation control treatment looked for effects of emasculation on hip set and development; however, since insects generally only forage on intact rose flowers (personal observation), pollination may not have occurred, causing the low numbers of hips seen. Rosa multiflora had a relatively high $17 \%$ hip set in this treatment, but it is possible that insects transferred pollen to the test stigmas while foraging on the numerous small, neighbouring, intact flowers. Rosa virginiana also had a similar hip set in the emasculation treatment $(16 \%)$, although the flowers in its' inflorescences are similar to those of $R$. blanda and $R$. canina, which only had 5\% and 4\% set respectively, suggesting an unknown factor was involved.

Rosa cinnamomea did not set fruit in any of the treatments or sites. Roland (1998) and MacPhail (2004) stated that $R$. cinnamomea does not form any fruit, possibly due to a lack of pollinators and/or self-incompatibility. Since hand pollinations did not result in hips, it is unlikely that pollinators are the issue. The origin of the patches tested is unknown, and so it is possible that they are clones of each other (e.g. having been originally propagated and distributed by humans); therefore, if they are self-incompatible, even "cross-pollination" would in fact be a form of incompatible self-pollination. Although Ueda and Akimoto (2001) and Jičínská (1976) found 25\% and 8.5\% selfed-fruit set, respectively, for $R$. cinnamomea, it is possible that the naturalized versions of $R$. cinnamomea tested in this study have different, non-phenotypic features than their native counterparts growing in Eurasia, causing the differing results. Additional Canadian sites need to be evaluated before any firm conclusions can be made.

\section{Insect Observations}

Thirteen sites (five species) were observed twice during the flowering period. Several sites did not have any visitors at certain time periods, although at least $77 \%$ of the sites had visitors from $0900-1400$ h (up from $62 \%$ at 0800 and 1500 , and $44 \%$ at 1600 ). When all of the visitation data were pooled and adjusted for varying flower numbers, the greatest average visitation rate (total number of visits/total number of flowers/total number of sites) was observed at $1100 \mathrm{~h}$ with 1.64 visits/flower/site over the 10 minutes (Fig. 2A). It was noted that bees, especially honeybees, were more active in the mid-late morning periods, which would translate into a greater visitation rate, not only because there are more insects foraging, but because bees often make quick visits to many flowers over a period of time, while hover flies visit and spend more time at fewer flowers in the same time period (data not presented here). The greatest average foraging rate (total seconds spent foraging on the flower/total number of flowers/total number of sites) was observed at $0900 \mathrm{~h}$, with an average visit lasting 189.64 seconds/flower/site (Fig. 2B). This sharp peak in foraging rate probably indicates when the anthers dehisced (i.e. when the most pollen was available). After this point, much of the pollen could have been removed, so insects would spend less time at each flower collecting pollen and more time searching for other more bountiful flowers. There were no significant differences between sites in the total number of insect visits/site, even after they were adjusted for the number of flowers being observed (K-W, $\mathrm{p}=0.107$ ) (Fig. 3).

Observed insects were fitted into one of seven groups, with an eight grouping being a place holder for periods with no recorded visitors. When all observations are considered together, the other bees grouping contained the most visits (459), followed by hover flies (268), honeybees (177), bumble bees \& large carpenter bees (136), other flies 
(92), (no visitors) (62), unknown/uncertain insect types (47), other insects (44), and beetles (32). This makes bees and hover flies more valuable as pollinators since there is a greater chance of pollen being dispersed to several different flowers on one foraging trip, especially compared to other flies and insects that do not forage as actively on pollen or are often just resting on the flowers.

Representatives of most floral visitors were also collected during the summer and are currently being identified. Thus far, identified bees from the 2004 field season include Andrena (Andrena) thaspii, Andrena (Euandrena) geranii, Andrena (Melandrena) vicina, Andrena (Plastandrena) crataegi, Andrena (Simandrena) wheeler, Andrena (Trachandrena) miranda, Apis mellifera, Augochlorella aurata, Bombus (Cullumanobombus) rufocinctus, Bombus (Pyrobombus) bimaculatus, Bombus (Pyrobombus) impatiens, Bombus (Pyrobombus) ternarius, Calliposis (Calliopsis) andreniformis, Ceratina (Zadontomerus) calcarata or dupla, Hylaeus spp., Lasioglossum (Dialictus) cressonii, Lasioglossum (Dialictus) laevissimum, Lasioglossum (Dialictus) near laevissimum, Lasioglossum (Evylaeus) cinctipes, Lasioglossum (Lasioglossum) zonulum, and Xylocopa (Xylocopoides) virginica.

\section{CONCLUSIONS}

Species in the genus Rosa were found to reproduce using different methods and to host a variety of insect visitors. Rosa blanda and $R$. multiflora were found to reproduce using open-pollination, geitonogamy and xenogamy, while $R$. canina and $R$. virginiana can utilize autogamy, open-pollination, geitonogamy and xenogamy, and $R$. cinnamomea does not appear to set hips. Both $R$. multiflora and $R$. virginiana produced one hip through asexual means. If any of these species are to be grown on a large scale for their hips, it must be kept in mind that $R$. blanda and $R$. multiflora will require external pollination, by hand or through insect visits, for large amounts of fruit to be produced, although $R$. canina and $R$. virginiana would also benefit. It was suggested that $R$. cinnamomea is selfincompatible, and that plants in both sites may be genetically identical. Due to the lack of hip production, it would not be a good crop candidate.

Insect visitation rates were highest in mid-morning, especially between 0900 and 1200 when the majority of bees were out foraging, and were not significantly different between sites. Foraging rates sharply peaked at 0900, which is thought to represent when the most pollen was available. The majority of insect visitors were either bees (Hymenoptera) or hover flies (Syrphidae), which are potentially good pollinators since they make frequent visits to many flowers, although beetles and other insects were also occasionally noted. Identified bee genera included Apis, Augochlorella, Bombus, Calliposis, Ceratina, Halictus, Hylaeus, Lassioglossum, and Xylocopa. Increased rose crop pollination could be achieved by introducing managed bees (e.g. honeybees) and by increasing native bee populations by providing unmanaged land (e.g. hedgerows, old fields) nearby for nesting. Since roses do not produce nectar, suitable nectar-producing plants should also be included into the site plan. Further work on this project is currently underway by the authors.

\section{ACKNOWLEDGMENTS}

Thanks to the Atlantic Canada Innovation Fund and the Atlantic Canada Network on Bioactive Compounds for financial and research assistance, to John S. Ascher and Sam Droege for bee identification, to James R. Kemp at the University of Prince Edward Island for lab space and discussions, and to Colleen Fuss for help in the field.

\section{Literature Cited}

Daels-Rakotoarison, D.A, Gressier, B., Trotin, F., Brunet, C., Luyckx, M., Dine, T., Bailleul, F., Cazin, M. and Cazin, J.C. 2002. Effects of Rosa canina fruit extract on neutrophil respiratory burst. Phytotherapy Research. 16(2):157-61.

Cole, P. and Melton, D. 1986. Self- and cross-compatibility relationships among genotypes and between ploidy of the rose. J. Amer. Soc. Hort. Sci. 111(1):122-125. 
Cutler, R.R. 2003. Medicinal and Pharmaceutical Uses. p 716-726. In: A.V. Roberts, T. Debener and S. Gudin (eds.), Encyclopedia of Rose Science, Vol. 2. Elsevier Academic Press, Oxford, United Kingdom.

Dafni, A. 1992. Pollination Ecology: A Practical Approach. Oxford University Press, New York.

Dafni, A., Kevan, P.G. and Husband, B.C. 2005. Practical Pollination Biology. Enviroquest, Ltd., Cambridge, Ontario, Canada.

Jičínská, D. 1975. Diversity of pollination in some Rosa species. Preslia. 47:267-274.

Jičínská, D. 1976. Autogamy in various species of the genus Rosa. Preslia. 48:225-229.

Kevan, P.G. 2003. Pollination. p 456-460. In: A.V. Roberts, T. Debener and S. Gudin (eds.), Encyclopedia of Rose Science, Vol. 2. Elsevier Academic Press, Oxford, United Kingdom.

Kevan, P.G., Eisikowitch, D., Ambrose, J.D. and Kemp, J.R. 1990. Cryptic dioecy and insect pollination in Rosa setigera Michx. (Rosaceae), a rare plant of Carolinian Canada. Biol. J. Linnean Soc. 40:229-243.

Kearns, C.A. and Inouye, D.W. 1993. Techniques for Pollination Biologists. University Press of Colorado, Colorado.

MacPhail, V. 2004. Distribution and Yield Analysis of Native and Naturalized Wild Roses (Rosa sp.) on Prince Edward Island. Honours BSc thesis, Dept. of Biology, Univ. of Prince Edward Island.

Richards, A.J. 1997. Plant Breeding Systems. Garland Science, UK.

Roland, A.E. 1998. Roland's Flora of Nova Scotia. (revised by Zinck, M.). Nimbus Publishing and Nova Scotia Museum.

Schneider, G. 1995. Native Trees and Shrubs: A Collection of Publications from the MacPhail Woods Ecological Forestry Project. Environmental Coalition of PEI, Charlottetown.

Stougaard, B. 1983. Pollination in Rosa multiflora. Tisskrift for planteavl. 87:633-642.

Ueda, Y. and Akimoto, S. 2001. Cross- and self-compatibility in various species of the genus Rosa. J. Hort. Sci. \& Biotech. 76(4):392-395.

Ueda, Y., Takeshita, D. and Ando, T. 1996. Pollination in Rosa rugosa Thunb. ex Murray. Acta Hort. 424:309-310.

Uggla, M. 2004. Domestication of wild roses for fruit production. Doctoral diss., Dept. of Crop Science, SLU. Acta Universitatis Agriculturae Suecia. Agraria 480.

Uggla, M. and Nybom, H. 1999. Domestication of a new crop in Sweden - dogroses (Rosa sect. Caninae) for commercial rose hip production. Acta Hort. 484:147-151.

Werlemark, G. 2003. Inheritance in the Dogrose. In: A.V. Roberts, T. Debener and S. Gudin (eds.), Encyclopedia of Rose Science, Vol. 1. Elsevier Academic Press, Oxford, United Kingdom.

Yeboah Gyan, K. and Woodell, S.R.J. 1987. Flowering phenology, flower colour and mode of reproduction of Prunus spinosa L. (Blackthorn); Crataegus monogyna Jacq. (Hawthorn); Rosa canina L. (Dog Rose); and Rubus fruticosus L. (Bramble) in Oxfordshire, England. Functional Ecology. 1(3):261-268.

Zheng, W. and Wang, S.Y. 2003. Oxygen radical absorbing capacity of phenolics in blueberries, cranberries, chokeberries, and lingonberries. J. Agr. and Food Chem. 51(2): 502-509. 


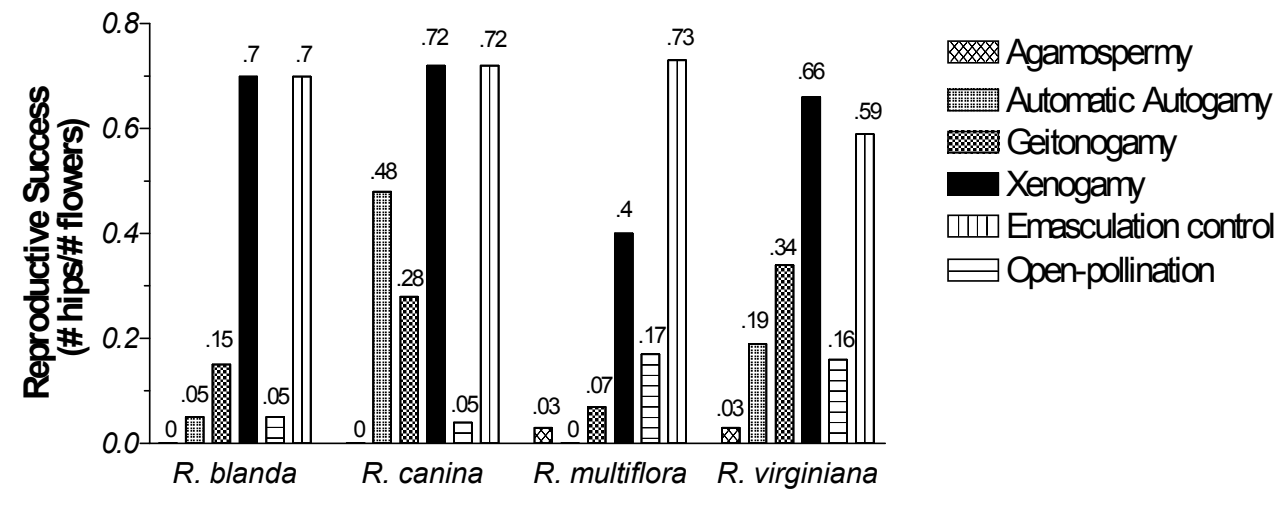

Fig. 1. Pooled reproductive success (\#hips formed/\#flowers tested) for agamospermy, automatic autogamy, geitonogamy, xenogamy, emasculation control and openpollination treatments for Rosa blanda (5 flowers/trt/site, 4 sites in Ontario, Canada), R. canina ( 5 flowers/trt/site, 5 sites in Ontario, Canada), R. multiflora (5 flowers/trt/site, 6 sites in Ontario, Canada), and $R$. virginiana ( 8 flowers/trt/site, 4 sites in Prince Edward Island, Canada) in 2004. Rosa cinnamomea (8 flowers/trt/site, 2 sites in Prince Edward Island, Canada) is not shown as it had zero reproductive success in all treatments.
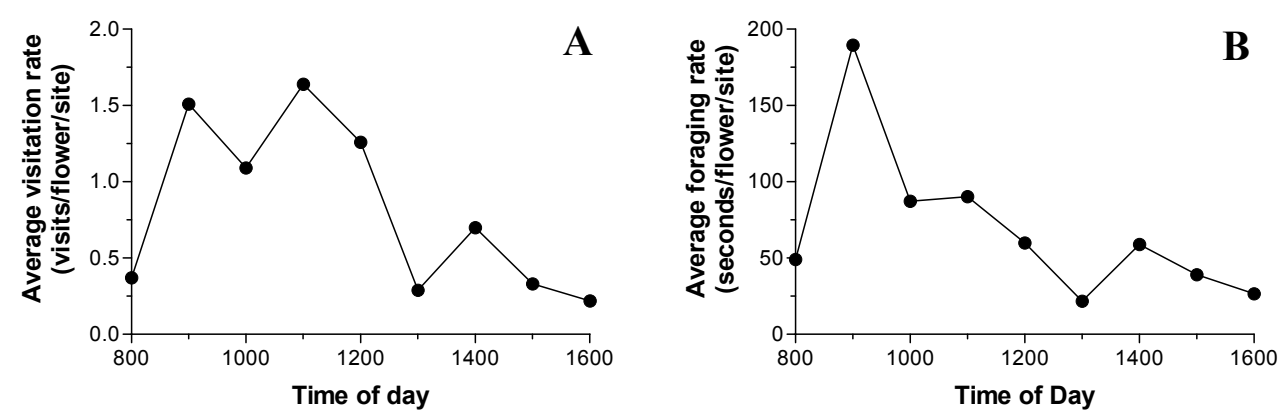

Fig. 2. Average visitation rates (visits/flower/site) (A) and average foraging rates (seconds/flower/site) (B) for all observed insects at each time period in Ontario and Prince Edward Island, Canada in 2004. Data has been pooled from all observations of Rosa blanda (2 sites), $R$. canina (5 sites), $R$. cinnamomea (2 sites), $R$. multiflora (2 sites), and $R$. virginiana (3 sites), and adjusted for varying numbers of flowers at each observation time. No distinction was made between insect types. Observations were carried out on fine-weather days in June, 2004 from 0800 to $1600 \mathrm{~h}$ for all sites except $R$. cinnamomea and $R$. virginiana, which ended at $1500 \mathrm{~h}$ and were carried out in July, 2004. 


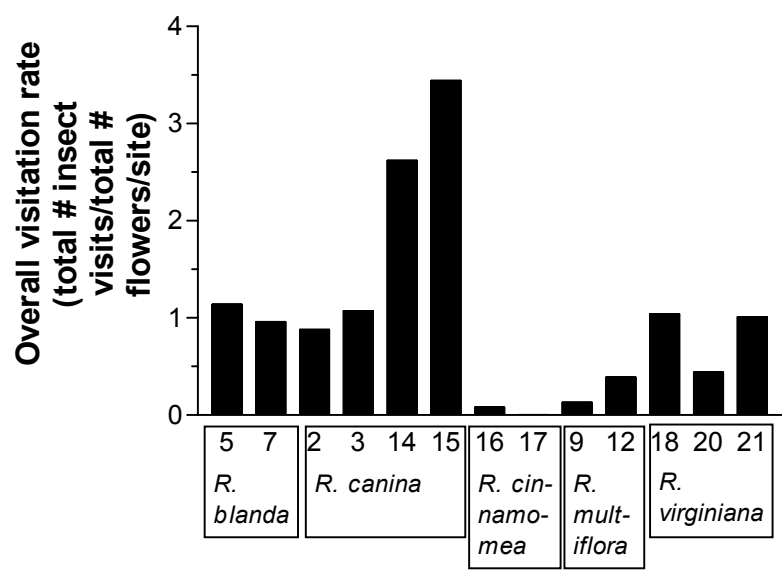

Site \#

Fig. 3. Overall visitation rate (total number of insect visits/total number of flowers/site), incorporating two observation days per site in 2004. Five different species were examined: $R$. blanda (sites 5, 7), $R$. canina (sites $2,3,14,15), R$. cinnamomea (sites 16, 17), $R$. multiflora (sites 9,12 ), and $R$. virginiana (sites 18, 20, 21). Data was pooled from all time periods, with no distinction made between insect types. Observations were carried out from 0800 to $1600 \mathrm{~h}$ for $R$. blanda, $R$. canina, and $R$. multiflora in Ontario, Canada, and from 0800 to $1500 \mathrm{~h}$ for $R$. cinnamomea and $R$. virginiana in Prince Edward Island, Canada. 